\title{
Innovative facade systems for buildings in hot climate conditions
}

\author{
Adham Giyasov* and Saidmuhammad Mirzoev
}

Moscow State University of Civil Engineering, Yaroslavskoe shosse, 26, Moscow, 129337, Russia

\begin{abstract}
The article considers the current state of construction of enclosing walls with facade systems for southern latitudes with a hot climate, taking into account the thermal air envelope formed at the walls of buildings of different orientations under the condition of facade insolation. The influence of the total temperature on the external enclosing structure of buildings, depending on their orientation and the conditions of insolation, is determined. The significance of the external walls of buildings under different conditions of facade insolation in the regulation of the heat-wind regime of the wall microclimatic layer of the air and the room is revealed. The list of facade systems for improving the ventilation of the wall layer of air, premises and the territory adjacent to the building, which are of crucial importance in ensuring the microclimatic comfort of the indoor environment in the problem of improving the energy efficiency of buildings, is formulated.
\end{abstract}

\section{Introduction}

This article is devoted to the study of the processes of formation of the heat-wind regime of the wall layer of air that forms a heat-protective shell, taking into account the dominant factor for the conditions of a hot climate of insolation and determining its relationship with the air environment of the room. The article describes innovative facade systems that increase the thermal stability of building walls, improve the internal heat regime, air exchange quality in the room, ensuring the appropriate level of illumination and the condition of insolation of premises.

This article discusses the current state of construction of enclosing walls with innovative facade systems for southern geographical latitudes with a hot climate condition, taking into account the thermal air envelope formed at the walls of buildings of different orientation under the condition of their insolation.

The main issue requiring disclosure is to determine the role of vertical walls of buildings and adjacent horizontal underlying surfaces of the building territory in the formation of a local microclimatic layer of air, which is the basis for regulating the heat and wind regime of the wall thermal air envelope and the building premises.

The use of solar energy in cities of southern geographical latitudes to create a favorable microclimate in homes and on the territory of urban development in the summer is one of the logical steps in solving the problem of improving the human environment.

\footnotetext{
${ }^{*}$ Corresponding author: adham52@mail.ru
} 
In the world construction practice in recent years, the construction of buildings with increased thermal protection properties is expanding, the purpose of which is to reduce the level of energy consumption for their operation. Advanced countries today focus on improving building standards to improve energy efficiency and ensure that construction projects meet them [1-6]. At the same time, one of the most important tasks is to study the dynamics of heat propagation in wall enclosing structures in this regard, the choice of design solutions for facade systems that form the thermal regime of buildings in the conditions of summer overheating is a priority.

The radiant energy of the sun on the territory of Asian, Central Asia, American, African, Arab and a number of other States extending in southern latitudes - from 0 to 45 northern latitude on the two sides of the equator is very peculiar: it is characterized by the maximum probability and duration of solar radiation, the greatest direct, total and reflected radiation, insignificant scattered radiation, etc. In this regard, the mode of solar irradiation of buildings and urban areas exposed to direct sunlight significantly affects the thermal state of the environment [7-10].

The inclusion of the thermal air envelope formed around the building envelope structures during their insolation in the process of designing external enclosing structures and buildings in General is an effective and very important way to achieve comfortable conditions for the thermal regime of buildings and minimize energy consumption in buildings [11-12].

In recent years, scientific research has focused on the development of engineering methods for calculating, compiling and solving mathematical models that reliably describe the thermophysical processes occurring in enclosing structures under the influence of external climatic factors [13-16].

The structural solution of exterior walls with effective facade systems, adopted at the initial design stage, is important for the construction of energy-efficient buildings, which are devoted to a number of works [17-22].

However, it should be noted that the issues of thermal protection properties of curtain facade systems and methods for calculating the thermal regime of enclosing structures in order to improve the efficiency of thermal protection of buildings in a hot climate in southern latitudes are not well studied.

\section{Methods}

In order to study the physical processes occurring under the condition of insolation of the external walls and the accompanying thermal heating of the external surface of the walls, causing the convective flows of the wall layer of air and ultimately determining the microclimate of the premises, the methods of field studies in the wall layer of air over the entire height and the mobility of air in the premises of multi-storey buildings were applied using the methods of actinometric, thermophysical and microclimatic studies. The research was carried out using modern portable devices: thermal infrared thermometer FLIR TG165, pyrometer GM1350, testo-610, digital thermometer EM 9020C, thermoelectric actinometer AT-50, anemometer AMTAST AMF001. 9 and 16-storey buildings of different orientations with vertical, horizontal, lattice and solid facade systems were accepted as objects of fullscale instrumental research. The studies were conducted in the summer period in JulyAugust.

\section{Results}

A building surrounded by a wall-mounted thermal air shell, depending on the conditions of insolation, is not uniform. If in the presence of wind, the pressure difference between the 
internal and external environment is created by complex conditions of air flow around the building, then in calm weather, which in cities of southern latitudes is $60 \ldots 80 \%$ of cases, the cause of thermal inhomogeneity of the walls is the irradiation conditions of building facades, creating a temperature difference between the surfaces of insolated and shadow facades (up to $20 \ldots 30^{\circ} \mathrm{C}$ ). The heat pressure in this case occurs due to the difference in the specific weights of the indoor air and the external wall-mounted microclimatic layer of air at a temperature difference of up to $20^{\circ} \mathrm{C}$ or more.

Architectural and structural elements play a significant role in the formation of the thermal regime of the air environment of premises: the design of walls and their orientation to the cardinal directions, the design of facade systems and materials, sun protection devices, the design of Windows (one -, two - and three-layer), transoms, vents and ways of opening them with a horizontal suspension or with a vertical suspension, opening in different directions.

Research in recent years has focused on the impact of solar radiation on buildings as a determining factor of climate and formation, with the thermal air envelope around it being an important climate factor. Consideration of thermophysical and aerodynamic processes occurring in the wall thermal air shell is a priority in correcting external climatic influences on buildings in General and in particular on external enclosing structures with and without facade systems.

In the CIS countries, to date, in assessing the energy efficiency of buildings, designers are based on climate data provided in regulatory documents when calculating the thermal stability of enclosing structures. However, as our study shows, urban landscape with a complex rough structure buildings of different heights in the southern latitudes, depending on the conditions insolation of exposure of the active surface of building walls, roofs, and Windows of buildings and paving of the local area, making adjustments to the energy factors determining the total temperature at the outer surface of the walls, it is important to consider at the design stage and buildings construction (Fig.1,2).

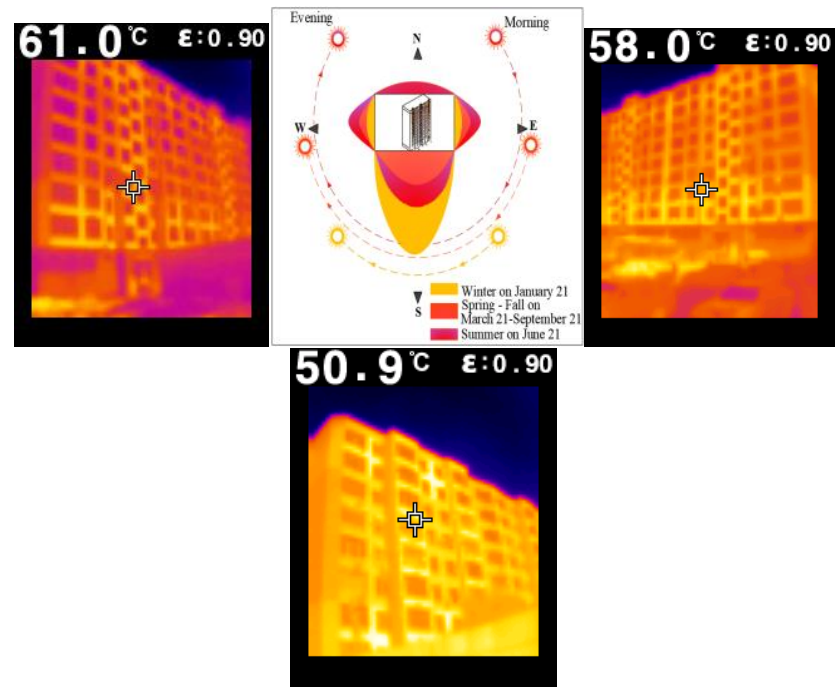

Fig. 1. Energy model insolation condition of building facades of different orientations. 


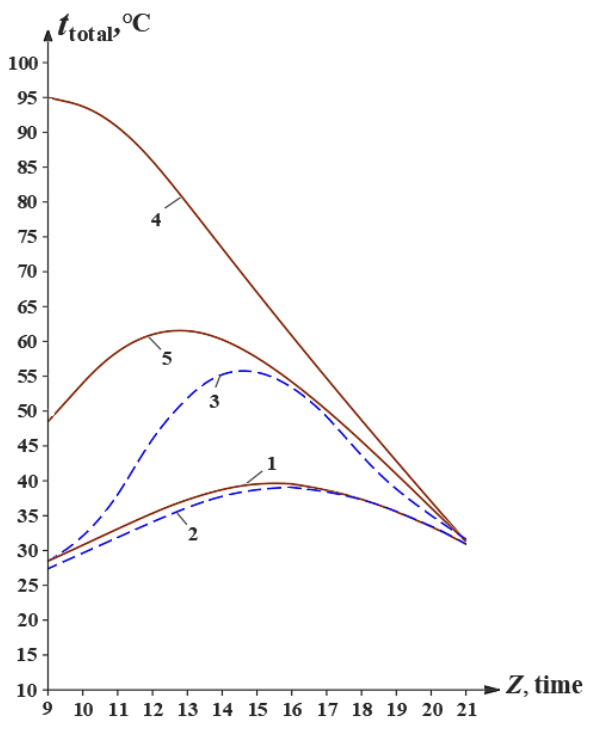

a.

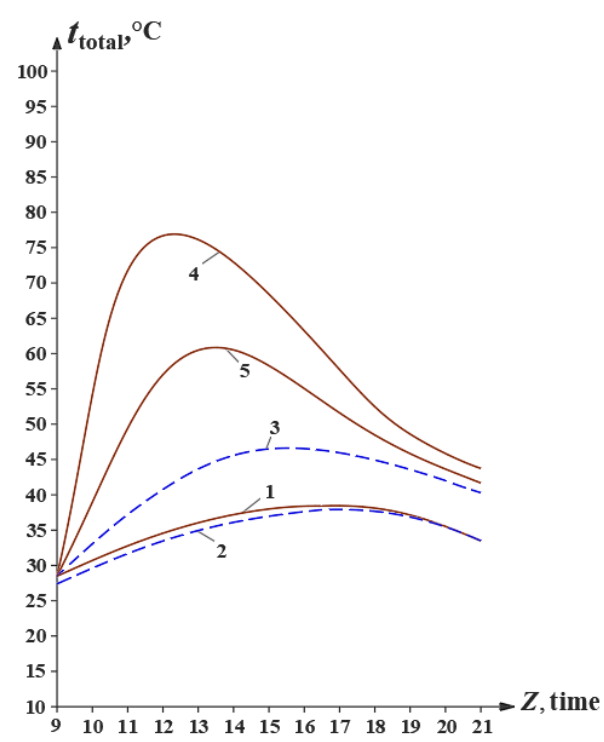

b.

Fig.2. The model daytime running total of the temperature on the outer surface of the wall West and East orientation (a) and South orientation (b), 1-air temperature in the area between the buildings, 2the same, a weather station, 3-temperature at the distance of $0.5 \mathrm{~m}$ from the wall, 4-total temperature $\left(\mathrm{t}_{\text {total }}=\mathrm{t}_{\mathrm{ext}}+\frac{\rho \mathrm{I}}{\alpha_{\mathrm{ext}}}\right.$ actual), 5 - the same with $\alpha_{\mathrm{ext}}=23.26 \mathrm{~W} / \mathrm{m}^{2}$ (standards).

In areas with a hot climate, a significant intensity of solar radiation $\left(980 \mathrm{~W} / \mathrm{m}^{2}\right.$ or more) combined with high summer temperatures $\left(40 \ldots 42{ }^{\circ} \mathrm{C}\right.$ in the shade), a high probability of long clear Sunny days and low wind speed $(2 \ldots 4 \mathrm{~m} / \mathrm{s})$ and humidity $(25 \ldots 30 \%)$ leads to overheating of the environment of buildings $\left(32 \ldots 34{ }^{\circ} \mathrm{C}\right)$ and urban development $\left(36 \ldots 38^{\circ} \mathrm{C}\right)$.

Duration superheated period in southern latitudes is $5 \ldots 8$ months with an average length of 28 to 30 days of sunshine, in which as shown by actinometric measurements conducted in the month of July, the intensity of solar radiation coming to the facades of buildings, oriented in different directions depending on the conditions of insolation changes - Western and Eastern orientation of $820 \mathrm{~W} / \mathrm{m}^{2}$, South $-560 \mathrm{~W} / \mathrm{m}^{2}$ and North $-160 \mathrm{~W} / \mathrm{m}^{2}$, which leads to heating of the outer surfaces of the walls, respectively, to $65^{\circ} \mathrm{C}, 55^{\circ} \mathrm{C}$ and $28{ }^{\circ} \mathrm{C} \mathrm{(Fig.3).}$

The thermal regime of building wall surfaces, depending on their orientation, forms its own microclimate of the wall layer of air, which has a direct connection with the internal air environment of the premises. Filtration processes are formed due to the influence of gravitational convection air thermal shell of buildings contributes to the pumping of the air through the window from the shadow of the Western façade and the room in the direction of the East insulinaemia of the facade and premises in the first half of daylight, and Vice versa, in the second half of the photoperiod pumping air through the Windows of the Eastern facade and shadow of the room, towards the Western insulinaemia of the facade and facilities. The wall of the Northern facade is almost in shadow during daylight during the entire warm period, in this regard, air is pumped through the Windows from the shadow of the Northern facade and the room to the southern facade and the room. This process of aeration of premises continues until the thermal balance of uneven heating of wall structures is established. With this aeration mechanism, the speed of air mobility in the premises is $0.25 \ldots 1.5 \mathrm{~m} / \mathrm{s}$, which makes it possible to provide the most rational condition for end-to-end ventilation of premises in the warm period of the year (Fig. 4.). 


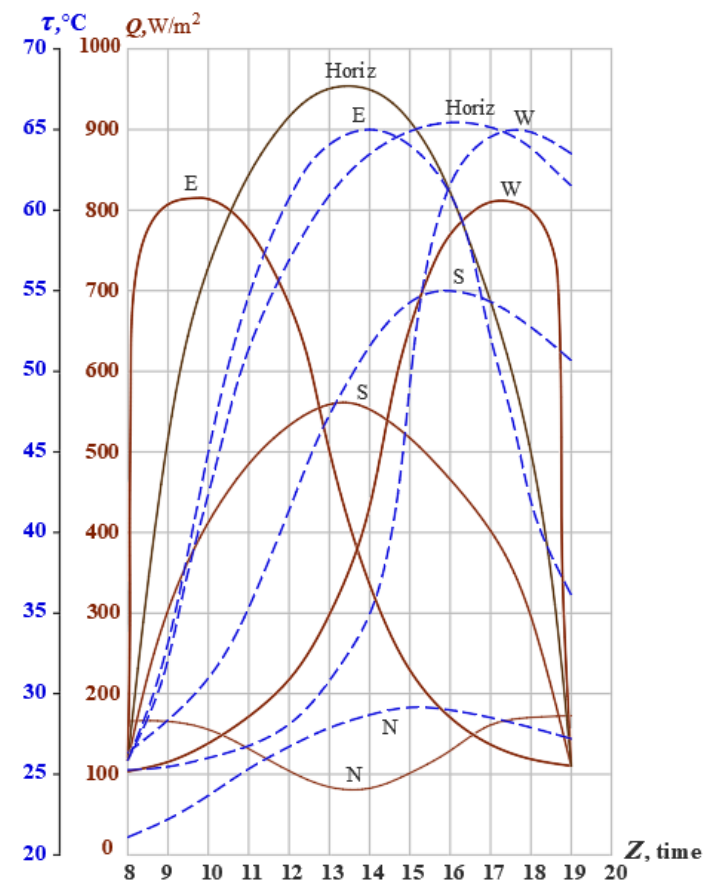

Fig. 3. Model of the daily course of solar energy -and thermal mode $=-=-$ - wall surfaces of different orientation.

Theoretical calculations made for rooms $16 \mathrm{~m}^{2}$ and a height of $3 \mathrm{~m}$ in panel buildings in the closed mode of operation show that average $35.5^{\circ} \mathrm{C}$, the value of the average daily heat gain through the South window area $2.25 \mathrm{~m}^{2}$ is $540 \mathrm{~W}$, over the North window $-245 \mathrm{~W}$, through the external wall North, West, East and South orientations of the room, respectively, 480, 790, 730 and $920 \mathrm{~W}$. Naturally, this amount of heat, introduced by solar energy in the summer, forms a thermal environment with indoor air temperature values up to $36{ }^{\circ} \mathrm{C}$ or more, which significantly exceeds the comfort values. With such thermal discomfort, natural aeration due to thermal pressure plays a significant role.

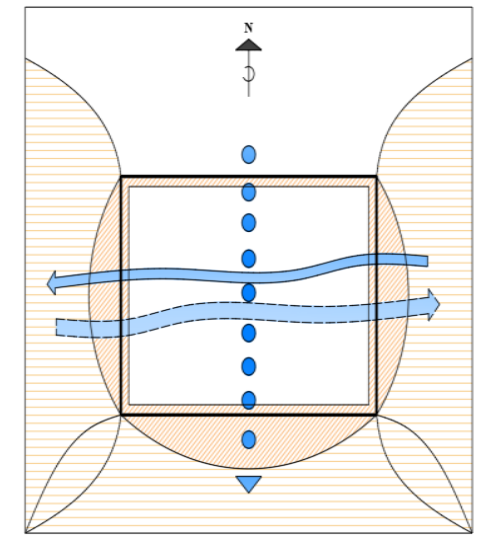

Fig. 4. Model aeration of buildings premises due to heat pressure:

Q zone of heat-wind disturbance from the insulated wall; $\square$ - zone of heat and wind disturbance from the insulated house territory; $>1>00$ - direction air exchange. 


\section{Discussion of results}

Protection of the exterior surfaces of the building walls from solar radiation has a great effect on reducing the flow of heat into the room in hot seasons.

Much attention is paid to the sun protection of external fences in domestic and foreign practice.

However, unfortunately, there are few examples of competent solutions for facade systems and sun protection devices that meet all the complex thermal, lighting, aeration, operational, artistic and other requirements. When designing buildings, there are often cases of underestimating or overestimating the role of anti-insulation agents in the fight against summer overheating. It should be noted that there are proposals for constructive solutions of the façade shading devices, efficient use of energy mechanism of the thermal shell wall microclimate air layer to increase the comfort of the indoor environment in the local area.

An important indicator of the thermal protection quality of anti-insulation facade devices is the coefficient of heat transmission of materials, which has a variable value that depends on the reflective properties of the surface of the material, the design of the device, the angle of incidence of sunlight. By shading the wall structures from direct sunlight, you can significantly reduce external thermal effects. This can be seen from the graph of the daily course of the total temperature (see Fig. 2).

Sun shields make it possible to dramatically lighten the external enclosing structures without compromising their thermal stability. They reduce the amplitude of temperature fluctuations on the inner surface of particularly light structures by 1.5-2 times.

The external surface of the walls of buildings is affected by the heat from the total solar radiation and the heat flow of the outside air, creating a so-called "thermal envelope" near the wall with its own heat-energy wall climate. The thermal air envelope differs from the standard value of this construction area in terms of climate indicators, in particular in terms of the maximum temperature at $15 \ldots 18{ }^{\circ} \mathrm{C}$ above the maximum air temperature of building standards for climatology. At the same time, convective flows that develop along the wall of the building at a speed of up to $3 \mathrm{~m} / \mathrm{s}$ at the level of the 9 th floor of the building differ from the standard wind speeds and direction. Environmental factors of the thermal air envelope have a direct connection with the internal environment of the room mainly through the translucent part by air exchange by infiltration and exfiltration, intense when open and less intense when closed operation of premises of buildings, forming a microclimate.

In residential buildings without regular ventilation, it is not possible to bring the microclimate of the building to the comfort zone.

External heat generated in the wall-mounted thermal air shell of the building is also infiltrated or exfiltrated through the external walls of the premises due to the cost, thermal conductivity of building materials and the design of the external enclosing walls.

The thermal air envelope is formed for both single-layer and multi-layer solid wall structures. In the wall structure of the facade system, thermal air shells are formed in the air layer between the facade screen system and the wall structure, as well as from the outside of the screen structure, their joint participation in the heat and energy processes of external fences plays a significant role. It is noted that the thermal air shells of enclosing structures are superimposed with a thermal convective flow from the adjacent territory when they are insolated.

\section{Conclusions}

Facade systems as the main component of building enclosing structures are anti-insolation means that separate the external environment from the internal, significantly improving the uncomfortable thermal regime of the indoor air environment. 
Analysis of the materials of full-scale thermophysical and microclimatic studies in the wall layer of air over the entire height of buildings and in the premises allowed:

- determine the effect of the total temperature on the enclosing structures of buildings, depending on their orientation. At the same time, on the wall of the western and eastern orientation, the total temperature reaches up to $95^{\circ} \mathrm{C}$ and the air temperature in the wall layer reaches up to $55{ }^{\circ} \mathrm{C}$, for the walls of the southern orientation, respectively, up to $76{ }^{\circ} \mathrm{C}$ and up to $47^{\circ} \mathrm{C}$;

- to identify the role of external walls of buildings in regulating the heat and wind regime of the wall layer of air and to determine the prerequisites for establishing the relationship between the microclimate of the external and internal environment under different conditions of facade insolation. At the same time, it is noted that due to the thermal regime of building facades with a wall heating temperature of $65^{\circ} \mathrm{C}$ or more, a wall-mounted convective flow is formed at a speed of $3 \mathrm{~m} / \mathrm{s}$ or more, which causes air mobility in oppositely located rooms at a speed of $0.08 \ldots 0.4 \mathrm{~m} / \mathrm{s}$ with a thermal head of $12 \mathrm{~Pa}$.

\section{Recommendations}

Thus, the possibility of evaluating the local thermal air envelope of the wall microclimatic layer of multi-storey buildings depending on the insolation conditions of the facade surfaces was determined, which allowed us to take into account the systematization of facade systems of different plastics according to their important thermodynamic and aerodynamic quality indicators (Table 1).

Table 1. Innovative facade systems of buildings with various plastics

\begin{tabular}{|c|c|c|c|}
\hline $\begin{array}{l}\text { № } \\
\text { ПП }\end{array}$ & Name & $\begin{array}{c}\text { Diagrams of the main } \\
\text { devices }\end{array}$ & General characteristic \\
\hline 1 & $\begin{array}{l}\text { Wall with remote } \\
\text { loggias }\end{array}$ & 3 & $\begin{array}{l}\text { Improvement of airing of premises and } \\
\text { significant deterioration of aeration of } \\
\text { premises with a loggia. Improving the } \\
\text { airing of the wall layer adjacent to the } \\
\text { building. Deterioration of the insolation } \\
\text { mode, illumination of rooms with a } \\
\text { loggia. Improving the thermal } \\
\text { conditions of rooms with a loggia. }\end{array}$ \\
\hline 2 & $\begin{array}{l}\text { Sunscreen devices are } \\
\text { solid along the entire } \\
\text { length of the facade }\end{array}$ & & $\begin{array}{l}\text { Effective protection of premises and } \\
\text { walls from high sun rays in summer, } \\
\text { providing insolation of premises in } \\
\text { winter. Satisfactory illumination of the } \\
\text { premises. Deterioration of the airing } \\
\text { conditions of the wall space, as well as } \\
\text { the territory adjacent to the building. }\end{array}$ \\
\hline
\end{tabular}




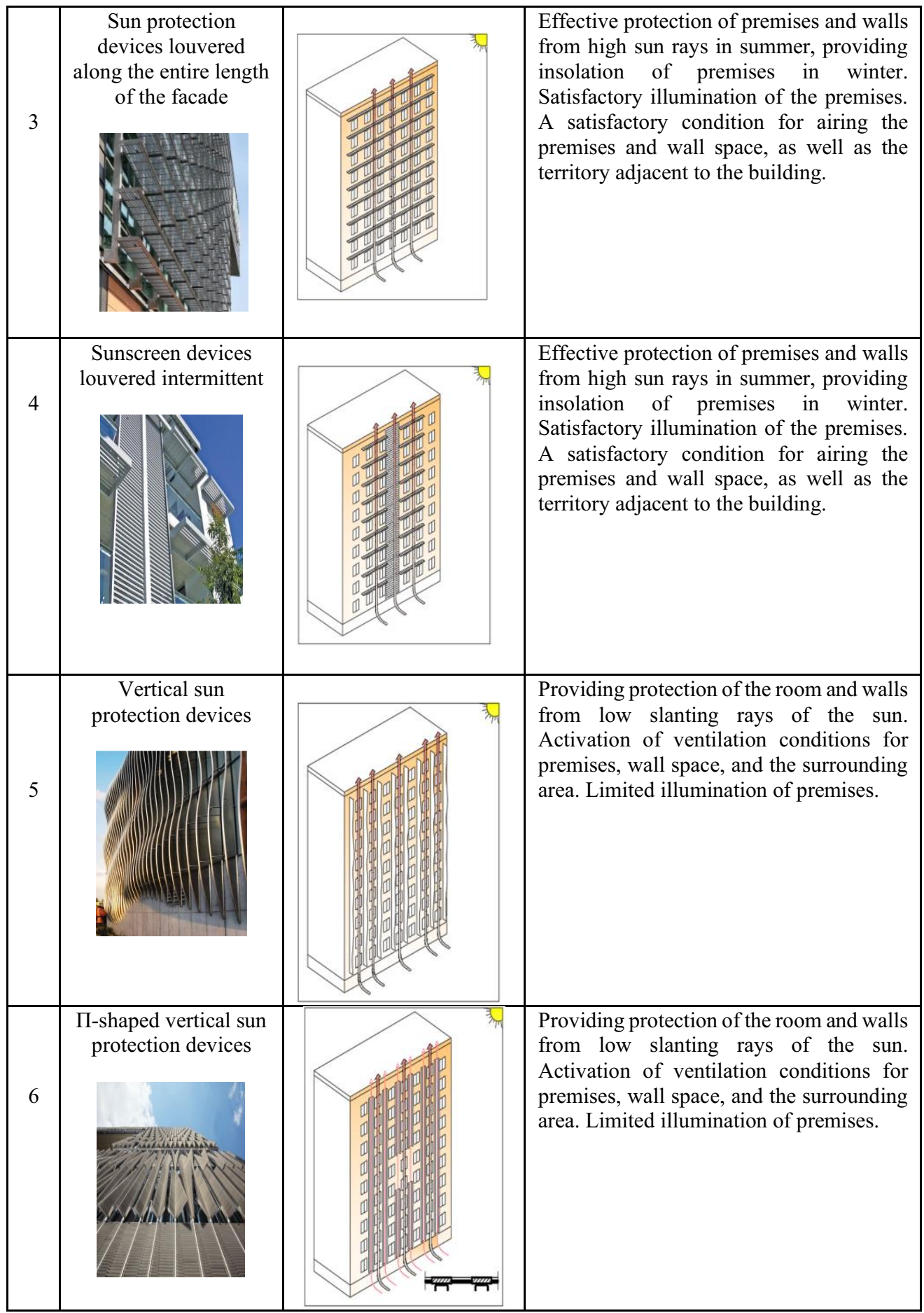




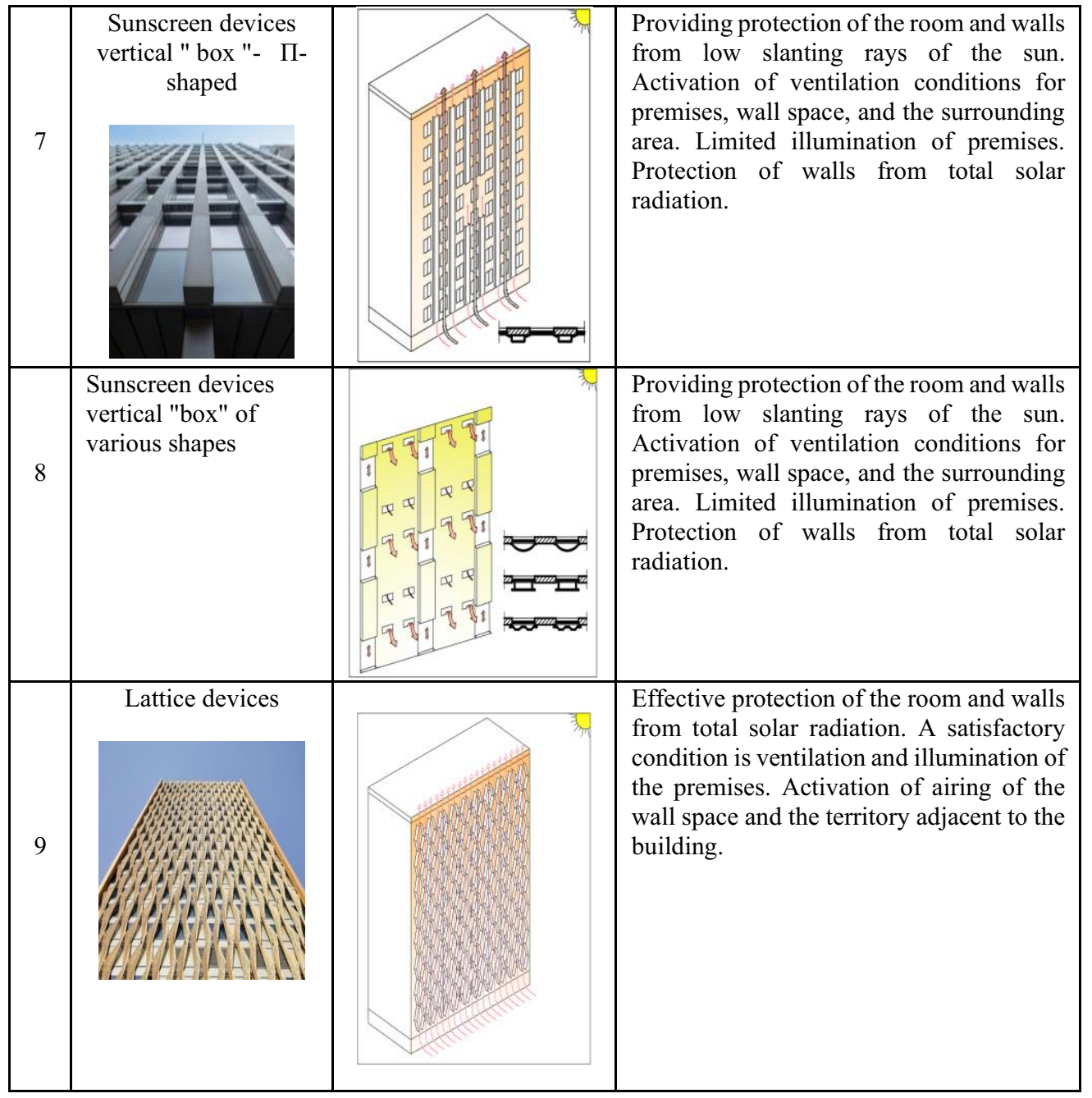

\section{References}

1. Yu.A. Tabunshchikov, Yu.V. Miller, Energy efficiency of buildings and structures, New sets of rules. Energy saving, 5, 21-25 (2013)

2. K.S. Ovchinnikov, Energy efficiency of thermal protection of residential buildings, Modern technologies in construction. Theory and practice, 1, 437-443 (2018)

3. A.S. Perevozchikova, E.O. Bazhenov, Retrofitting buildings to improve energy efficiency and extend the life of residential buildings, International Scientific Review,7, 10-14 (2017)

4. L. Gustavsson, A. Dodoo, N.L.Truong, I. Danielski, Primary energy implications of enduse energy efficiency measures in district heated buildings, Energy and Buildings, 1, 3848 (2011)

5. V. Dragisic, Improved energy efficiency and optimization of microclimate in buildings, MATEC Web of Conferences, 01044 (2016) 
6. A.Y. Zhigulina, A.M. Ponomarenko, E.N. Borodacheva, Problems of energy efficiency of residential buildings, IOP Conference Series: Materials Science and Engineering, 032020 (2020)

7. V.V. Stadnik, V.V. Elistratov, Renewable energy resources. Proceedings of the Main Geophysical Observatory, 574, 179-223 (2014)

8. J.-Y. Ma, Y. Luo, H. Liang, S.-K. Li, Variation trend of direct and diffuse radiation in china over recent 50 years, Wuli Xuebao, 6, 069601 (2011)

9. M.N. Morozov, P.A. Strizhak, Investigation of the influence of insolation heat input in order to improve the heat supply control system of the building, Industrial power engineering, 2, 52-57 (2016)

10. D.S. Strebkov, Prospects for the creation of a global solar energy system, Technical opponent, 1, 14-23 (2018)

11. V.G. Gagarin, V.V. Kozlov, On the complex indicator of thermal protection of the building envelope, Ventilation, heating, air conditioning, heat supply and construction thermal physics, 4, 52-61 (2010)

12. A.M. Beregovoy, V.A. Beregovoy, The choice of structures for external fences, taking into account energy savings in conditions of adverse environmental influences, Regional architecture and construction, 1, 86-90 (2019)

13. D.T.Sharipova, Development of methods for calculating the thermal regime of enclosing structures in order to improve the efficiency of thermal protection of buildings in the dry hot climate of Uzbekistan. Abstract for the degree of doctor of philosophy in technical Sciences, 20 (2018)

14. W. Guoa, X. Qiaoa, Y. Huanga, M. Fanga, X. Hanb, Study on energy saving effect of heat-reflective insulation coating on envelopes in the hot summer and cold winter zone, Energy and Buildings, 50, 196-203 (2012)

15. A. Giyasov, Heat and wind regime of the city canyon, its relationship with the air environment of premises, Engineering Bulletin of the don, 1, 13 (2018)

16. A.R. Masyonene, A.I. Masyonis, Use of solar-protective structures in transparent facades of the big area for passive compensation heat loss to maintain a comfortable microclimate of premises, International Research Journal, 8 , 83-85 (2019)

17. V.Yu. Domozhilov, Ventilated facade systems and their joint work with the structures of the BST building, Bulletin of building technology, 5, 52-53 (2019)

18. E.I. Panchenko, V.N. Tarasenko, Technological facade systems in designing of bionic volumes. East European Scientific Journal, 3, 5-7 (2017)

19. S.V. Korniyenko, T.N. Astafurova, O.P. Kozlova, Thermal renovation of facade systems in block buildings, IOP Conference Series: Materials Science and Engineering. International Science and Technology Conference "FarEastCon 2019", 022026 (2020)

20. I.Sh. Alirzaev, K.V. Makarychev, M.M. Dzhumakulieva, Facade systems as a tool to improve the energy efficiency of a building, Science sphere, 12, 2, 143-147 (2020)

21. S.A. Khlobystov, The main types of ventilated facade systems, the most effective for the Russian Federation and for St. Petersburg in terms of thermal energy efficiency. Bulletin of modern science, 9, 21, 62-69 (2016)

22. V.M. Tusnina, D.A. Emelianov, The seismic stability of facade system with facing by composite panels, Magazine of Civil Engineering, 4, 62-72 (2018) 